Original Article

\title{
Effect of platelet concentration on clinical improvement in treatment of early stage-knee osteoarthritis with platelet-rich plasma concentrations
}

\author{
Bahar Dernek, MD, PhD ${ }^{1 *}$, Fatma Nur Kesiktas, MD, $\mathrm{PhD}^{2)}$, \\ Tahir Mutlu Duymus, MD, PhD ${ }^{3)}$, Tugba Aydin, MD, $\mathrm{PhD}^{4)}$, \\ Nilgun Isiksacan, MD, PhD ${ }^{5}$, Demirhan Diracoglu, $\mathrm{MD}, \mathrm{PhD}^{6}$, Cihan Aksoy, MD, PhD ${ }^{6}$ \\ 1) Istanbul Kanuni Sultan Suleyman Training and Research Hospital, Physical Therapy and \\ Rehabilitation Clinic: Halkal, Istanbul, Turkey \\ 2) Istanbul Physical Medicine and Rehabilitation Training Hospital, Turkey \\ 3) Istanbul Kanuni Sultan Suleyman Training and Research Hospital, Orthopedics and Traumatology \\ Clinic, Turkey \\ 4) Okmeydani Training and Research Hospital, Physical Therapy and Rehabilitation Clinic, Turkey \\ 5) Department of Biochemistry, Bakirkoy Dr. Sadi Konuk Training and Research Hospital, Turkey \\ 6) Department of Physical Medicine and Rehabilitation, Istanbul Faculty of Medicine, Istanbul \\ University, Turkey
}

\begin{abstract}
Purpose] To compare two platelet-rich plasma kits with different platelet concentrations for treatment of knee osteoarthritis. [Subjects and Methods] Male and female patients with knee osteoarthritis who had confirmed diagnosis with X-ray and magnetic resonance imaging were included in this retrospective study. Eligible patients were divided into two groups: Group I, which received platelet-rich plasma kit I, and Group II, which received platelet-rich plasma kit II. Platelet concentrations of both kits were measured by manual counting. For each group, platelet-rich plasma kit was injected twice with a one-month interval between injections. The Western Ontario and McMaster Universities Osteoarthritis Index and the Visual Analog Scale were applied for clinical evaluation before the first injection and one, three and six months after the second injection. [Results] Kits I and II contained 1,000,000 and 3,000,000 platelets/ $\mu 1$ respectively. In both groups, initial Western Ontario and McMaster Universities Osteoarthritis Index and Visual Analog Scale scores were significantly higher compared to the latter evaluations. However, no significant difference was observed between groups in terms of clinical evaluations. [Conclusion] Similar clinical results were found in groups receiving different platelet concentrations, therefore, a concentration of 1,000,000 platelet/ $\mu 1$ is considered sufficient for pain relief and functional recovery. Key words: Knee, Osteoarthritis, Platelet-rich-plasma
\end{abstract}

(This article was submitted Jan. 4, 2017, and was accepted Feb. 16, 2017)

\section{INTRODUCTION}

Osteoarthritis (OA) of the knee is a progressive disease involving the intra-articular (IA) tibiofemoral and patellofemoral cartilage $^{1)}$. Conservative treatment modalities are the first choice in younger and middle-aged populations with cartilage damage and OA of the $\mathrm{knee}^{2)}$. Treatment of knee OA includes non-pharmacological methods such as exercise and lifestyle

\footnotetext{
*Corresponding author. Bahar Dernek (E-mail: bahardernek@gmail.com)

(C)2017 The Society of Physical Therapy Science. Published by IPEC Inc.

This is an open-access article distributed under the terms of the Creative Commons Attribution Non-Commercial No Derivatives (by-nc-nd) License. (CC-BY-NC-ND 4.0: http://creativecommons.org/licenses/by-nc-nd/4.0/).
} 
modification, as well as pharmacological therapies, such as analgesics, non-steroidal and steroidal anti-inflammatory drugs, and corticosteroid injections. The pharmacological therapies often have side effects and sometimes do not provide adequate benefits $^{3,4)}$.

Platelet-rich plasma (PRP) has been gaining popularity in treatment of knee OA due to its simplicity, safety and minimally invasive features ${ }^{5)}$. PRP is an autologous blood product with an elevated platelet (PLT) concentration that contains many different granules ${ }^{6,7)}$. PLT granules include a variety of growth factors (GFs), including PLT-derived GF, transforming GFbeta, insulin-like GF-1, and epidermal GF. The concentrations of these GFs may vary between patients and within the same patient at different times. These molecules are believed to be important in maintaining joint homeostasis, tissue healing and tissue regeneration ${ }^{8}$. PLT granules also store substances such as adenosine diphosphate, adenosine triphosphate, histamine, dopamine, serotonin, cathespin D, cathespin E, elastases and hydrolases, which are believed to play an important role in tissue regeneration $^{8-10)}$.

PLT concentration is mentioned in the literature as an important factor in PRP treatment. Scientific evidence is currently limited with regard to optimal PLT concentration for the treatment of knee OA and requires further investigation. Although in vitro studies reveal that PRPs with higher PLT concentrations release more GFs than PRPs with lower concentrations $(4.69 \times$ versus $1.99 \times$ concentrated PLTs), it remains unclear whether more GFs yield better clinical results ${ }^{11)}$.

The Western Ontario and McMaster Universities Osteoarthritis Index (WOMAC) questionnaire is one of the most widely used tools for evaluation of patient's functional status in rheumatic diseases, especially knee OA. Domains of stiffness, pain and functional limitation are measured in this questionnaire ${ }^{12}$. Similarly, the Visual Analogue Scale (VAS) is frequently used to evaluate clinical outcomes.

The aim of this study was to use WOMAC and VAS evaluations to compare the clinical outcomes of early stage-knee OA patients treated with two PRP kits with different PLT concentrations.

\section{SUBJECTS AND METHODS}

Data from male and female patients with knee OA (Kelgrenn Lawrence stage II and III) who were admitted to our physical therapy and rehabilitation clinic and diagnosed by clinical examination and X-ray imaging between January 2013 and December 2014 were retrospectively included in this study. Patients who did not have routine clinical evaluations (pre- and post-treatment WOMAC and VAS) were excluded from the study. Magnetic resonance imaging (MRI) records were also used for excluding joint effusion, meniscal degeneration, anterior cruciate ligament oedema and other knee injuries which may result in knee pain.

Patients were divided into two groups. Group I patients who received the Easy PRP Kit (Neotec Biotechnology Ltd., Istanbul, Turkey) and Group II patients received the Ycellbio PRP Kit (Ycellbio MEDICAL Co. Ltd., Seoul, South Korea).

For preparation of the Ycellbio PRP $\mathrm{kit}^{\circledR}, 3-4 \mathrm{ml}$ of PRP with a concentration of 9-13 times the average normal value, and $2 \mathrm{ml}$ of anticoagulant were drawn into a $20-\mathrm{ml}$ syringe. Then, $14 \mathrm{ml}$ of blood was collected from the patient. In total, a blood sample of $16 \mathrm{ml}$ was carefully injected at a $45^{\circ}$ angle into a Ycellbio kit ${ }^{\circledR}$. The sample was centrifuged at 3,700 rpm for seven minutes to concentrate the PLTs. Using the control lever in the bottom of the Ycellbio kit ${ }^{\circledR}, 3-4 \mathrm{ml}$ of PRP containing leucocytes was raised to the mid-line and drawn into a $5 \mathrm{ml}$ syringe. The injection site was prepared, and the PRP was injected under sterile conditions using a $22 \mathrm{G}$ needle in the classic approach for IA knee injections (Fig. 1). For preparation of the Easy PRP kit ${ }^{\mathbb{R}}, 1-3 \mathrm{ml}$ of PRP with a concentration of 4-6 times the average normal value, and $8.5 \mathrm{ml}$ of blood were collected. Then, $1.5 \mathrm{ml}$ of ACD-A was added to the sample as an anticoagulant. The prepared Easy PRP Kit ${ }^{\mathbb{R}}$ was centrifuged for five minutes at 1,200 RCF. Afterward, the blood was separated into plasma and red blood cells (RBCs). Next, RBCs, which are collected in the RBC collector section, were discarded from the device. In order to concentrate PLTs, a second centrifuge process was performed for 10 minutes at 1,200 RCF. The final product was 1-3 ml of PRP containing leucocytes. An exogenous factor was not used for the process of activation, but allowing the PLTs to be in direct contact with the joint collagen helped the activation. The injection site was prepared, a local anesthetic injection was administered, and the PRP was injected under sterile conditions using a $22 \mathrm{G}$ needle in the classic approach for IA knee injections. For each patient, the anesthetic injection consisted of $2 \mathrm{cc}$ of a mixture of $0.5 \mathrm{cc}$ lidocaine and $5 \mathrm{cc}$ of physiological serum.

Each patient was injected twice by the same physiatrist with a four week interval between injections. The PLT concentration of the two different PRP kits was evaluated by manual counting in the same microbiology laboratory.

The WOMAC and the VAS were applied for objective clinical evaluation before the first injection and one, three, and six months after the second injection. Patients were asked to complete the 24-question WOMAC osteoarthritis index questionnaire, which assesses pain, stiffness, and physical functions of OA. Higher WOMAC scores indicate impairment of the measured function. Level of pain was evaluated by the patients using a VAS with a 10-cm line with 'no pain' at one end and 'worst pain' at the other end.

This study was conducted in accordance with Declaration of Helsinki and approved by the ethics committee of Istanbul Kanuni Sultan Suleyman Training and Research Hospital with approval number KAEK/2014/2. A written informed consent was obtained from each subject.

The Kolmogorov-Smirnov test was used to evaluate the distribution of variables. For the analysis of quantitative data, the Mann-Whitney U test was used. Qualitative data were analyzed using the $\chi^{2}$ test. For descriptive statistics of the data, mean, 


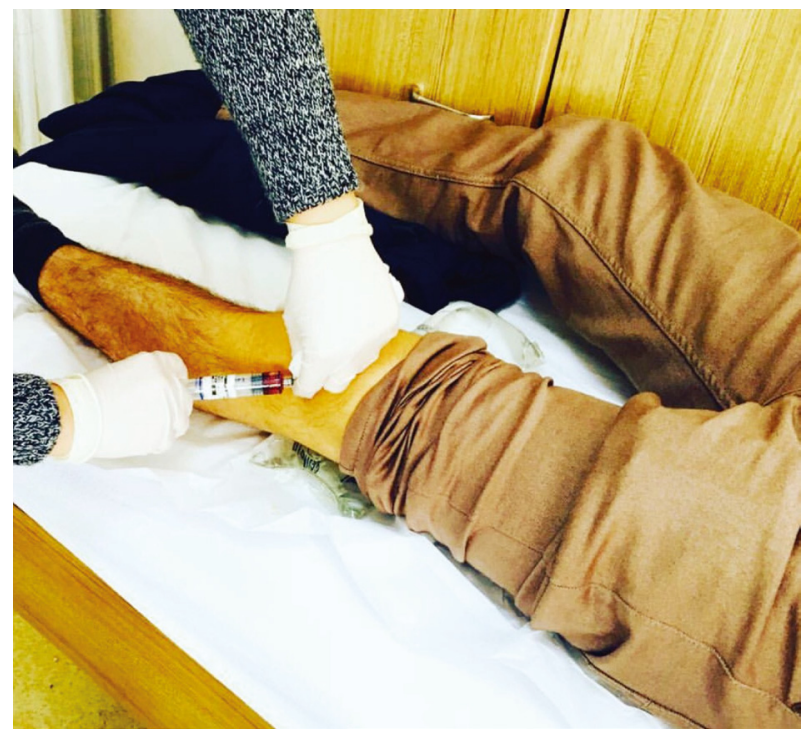

Fig. 1. Intraarticular injection technique

The knee is slightly flexed while the patient is in supine position. The patella is stabilized and the needle is inserted underneath the supralateral surface of the patella. The needle is aimed toward the center of the patella, and then directed into the knee joint.

Table 1. Demographic features

\begin{tabular}{|c|c|c|c|c|c|c|c|c|c|}
\hline \multirow{3}{*}{ Age } & & \multicolumn{4}{|c|}{ Group I } & \multicolumn{4}{|c|}{ Group II } \\
\hline & & \multicolumn{2}{|c|}{ Mean $\pm \mathrm{SD} / \mathrm{n}(\%)$} & \multicolumn{2}{|c|}{ Med (Min-Max) } & \multirow{2}{*}{\multicolumn{2}{|c|}{$\begin{array}{c}\text { Mean } \pm \text { SD/n (\%) } \\
60.4 \pm 5.5\end{array}$}} & \multicolumn{2}{|c|}{ Med (Min-Max) } \\
\hline & & 56.4 & 6.8 & 58 & $45-69$ & & & 61 & $49-69$ \\
\hline \multirow{2}{*}{ Gender } & Female & 19 & $95 \%$ & & & 24 & $96 \%$ & & \\
\hline & Male & 1 & $5 \%$ & & & 1 & $4 \%$ & & \\
\hline \multirow{3}{*}{ Affected joint } & Right & 3 & $15 \%$ & & & 5 & $20 \%$ & & \\
\hline & Left & 14 & $70 \%$ & & & 3 & $12 \%$ & & \\
\hline & Bilateral & 3 & $15 \%$ & & & 17 & $68 \%$ & & \\
\hline
\end{tabular}

standard deviation, median, minimum, maximum, frequency and ratio values were used. SPSS 22.0 software (IBM, Armonk, NY, USA) was used for analysis.

\section{RESULTS}

A total of 20 patients (19 females) were treated in Group I, and 25 patients ( 24 females) were treated in Group II. Mean ( \pm SD) age of the patients was $56( \pm 6.8)$ years in Group I, and $50( \pm 5.5)$ years in Group II. There were no significant differences between the two groups in terms of gender and age ( $>0.05$; Table 1$)$.

In both groups, the initial WOMAC total and subgroup scores for pain, stiffness, and function were higher at pre-injection evaluation when compared to the evaluations performed one, three, and six months after the second injection. WOMAC scores were reduced by more than $50 \%$ for each group, and these reductions were significant in each group ( $<<0.05$ ). However, no significant difference was observed between Group I and Group II in terms of WOMAC total and subgroup scores ( $>0.05$; Table 2).

Like the WOMAC scores, VAS scores of the patients reduced significantly $(p<0.05)$ after the treatment in both groups when compared to pre-injection evaluations. No significant difference $(p>0.05)$ was detected between the two treatment groups in terms of VAS evaluations performed at pre-injection, or one, three, and six months after the second injection (Table 3).

\section{DISCUSSION}

There is no consensus regarding a standard regimen of PRP treatment in musculoskeletal disorders. When using PRP as 
Table 2. The Western Ontario and McMaster Universities Osteoarthritis Index (WOMAC) evaluations of Group I and Group II

\begin{tabular}{|c|c|c|c|c|c|c|}
\hline & \multicolumn{3}{|c|}{ Group I } & \multicolumn{3}{|c|}{ Group II } \\
\hline & \multirow[t]{2}{*}{ Mean \pm SD } & \multicolumn{2}{|c|}{ Med (Min-Max) } & \multirow[t]{2}{*}{ Mean \pm SD } & \multicolumn{2}{|c|}{ Med (Min-Max) } \\
\hline \multicolumn{5}{|l|}{ WOMAC pain } & & \\
\hline Pre-injection & $15.3 \pm 3.0$ & 15 & $10-20$ & $16.1 \pm 2.6$ & 15 & $12-25$ \\
\hline 1 month & $7.5 \pm 2.1$ & $7 *$ & $5-15$ & $6.9 \pm 1.9$ & $7 *$ & $0-10$ \\
\hline 3 months & $7.3 \pm 0.9$ & $7 *$ & $5-9$ & $7.4 \pm 2.2$ & $7 *$ & $0-13$ \\
\hline 6 months & $7.0 \pm 0.0$ & $7 *$ & $7-7$ & $7.0 \pm 0.0$ & $7 *$ & $7-7$ \\
\hline \multicolumn{7}{|c|}{ WOMAC stiffness } \\
\hline Pre-injection & $6.0 \pm 1.7$ & 6 & $2-8$ & $6.2 \pm 1.2$ & 6 & $3-10$ \\
\hline 1 month & $3.2 \pm 0.8$ & $3^{*}$ & $2-6$ & $2.9 \pm 0.9$ & $3^{*}$ & $0-4$ \\
\hline 3 months & $3.2 \pm 0.4$ & $3^{*}$ & $3-4$ & $3.1 \pm 1.1$ & $3^{*}$ & $0-6$ \\
\hline 6 months & $3.2 \pm 0.4$ & $3^{*}$ & $3-4$ & $3.4 \pm 0.5$ & $3^{*}$ & $3-4$ \\
\hline \multicolumn{7}{|c|}{ WOMAC function } \\
\hline Pre-injection & $52.7 \pm 12.1$ & 51 & $34-68$ & $54.0 \pm 9.8$ & 51 & $34-85$ \\
\hline 1 month & $21.0 \pm 6.2$ & $19^{*}$ & $17-44$ & $20.0 \pm 7.2$ & $19^{*}$ & $0-34$ \\
\hline 3 months & $22.5 \pm 3.6$ & $21^{*}$ & $19-33$ & $22.7 \pm 6.0$ & $19^{*}$ & $16-35$ \\
\hline 6 months & $19.0 \pm 0.0$ & $19^{*}$ & $19-19$ & $19.0 \pm 0.0$ & $19^{*}$ & $19-19$ \\
\hline \multicolumn{7}{|l|}{ WOMAC total } \\
\hline Pre-injection & $74.0 \pm 16.2$ & 72 & $48-96$ & $76.3 \pm 13.5$ & 72 & $49-120$ \\
\hline 1 month & $31.6 \pm 9.0$ & $29^{*}$ & $24-65$ & $29.8 \pm 9.7$ & $29^{*}$ & $24-48$ \\
\hline 3 months & $32.9 \pm 4.0$ & $29^{*}$ & $29-45$ & $33.2 \pm 8.3$ & $29 *$ & $16-54$ \\
\hline 6 months & $29.2 \pm 0.4$ & $29 *$ & $29-30$ & $29.4 \pm 0.5$ & $29 *$ & $29-30$ \\
\hline
\end{tabular}

Mann-Whitney U test/Wilcoxon test

*Significant difference $(\mathrm{p}<0.05)$ when compared to the pre-injection evaluation of the same group

Table 3. Visual Analogue Scale (VAS) evaluations of Group I and Group II

\begin{tabular}{|c|c|c|c|c|c|c|}
\hline & \multicolumn{3}{|c|}{ Group I } & \multicolumn{3}{|c|}{ Group II } \\
\hline & Mean \pm SD & $\mathrm{Mec}$ & Min-Max) & Mean \pm SD & $\mathrm{Me}$ & (in-Max) \\
\hline \multicolumn{7}{|l|}{ VAS } \\
\hline Pre-injection & $7.2 \pm 1.2$ & 7 & $5-9$ & $7.4 \pm 1.1$ & 7 & $4-9$ \\
\hline 1 month & $3.6 \pm 0.5$ & $4 *$ & $3-4$ & $3.7 \pm 0.8$ & $4^{*}$ & $1-5$ \\
\hline 3 months & $3.5 \pm 0.5$ & $3 *$ & $3-4$ & $3.0 \pm 0.7$ & $3 *$ & $1-4$ \\
\hline 6 months & $2.7 \pm 0.5$ & $3^{*}$ & $2-3$ & $2.6 \pm 0.5$ & $3^{*}$ & $2-3$ \\
\hline
\end{tabular}

Mann-Whitney U test/Wilcoxon test

*Significant difference $(\mathrm{p}<0.05)$ when compared to the pre-injection evaluation of the same group

a treatment for OA, there are many variables to consider. These include preparation method, needle gauge for injection, PLT concentration, PLT granule secretion variability, leucocyte concentration, PLT storage, anticoagulant use, PLT pre-activation, local anesthesia use, image guidance use, injection volume, injection frequency, pre-injection and post-injection protocol, severity of OA being treated, and other patient factors ${ }^{13)}$.

In different studies, the average series of injections ranged from two to three at intervals of two to six weeks ${ }^{14-16)}$. In this study, two injections separated by a four week interval were used, to allow sufficient time to alleviate the patients' symptoms. This protocol was chosen because inflammatory processes and patient symptoms are usually improved in two weeks ${ }^{15}$.

Two different PRP kits were used in this study, so two different centrifuge devices with different volumes of blood were used. Needle gauge may affect the activation of PLTs, and blood collection with small-gauge needles may lead to premature activation of PLTs ${ }^{11)}$. Needle gauge is considered to be important for timing of GF release, since most GFs are released 10 minutes after activation ${ }^{6}$. To prevent this early activation, larger needles (at least $21 \mathrm{G}$ ) may be used and in combination with slow aspiration for blood harvest ${ }^{17}$. To our knowledge, there are no solid data on the effect of needle gauge while administering PRPs, and further research is necessary to determine needle gauge effect on PLT activation ${ }^{17}$. However, to eliminate any 
possible bias, the needle size $(22 \mathrm{G})$ was used for both blood harvest and PLT injection in both groups.

PLT concentration is one of the most topical factors in PRP treatment. PLT concentration in the published literature on knee OA has been variable and not consistently reported. Some authors suggest that the PRP PLT concentration should be at least two times the whole blood PLT concentration; however, concentrations up to eight times that of blood levels have been reported with good results ${ }^{18,19)}$. There is in vitro evidence that PRP with higher PLT concentration (4.69x) releases more GFs than PRP with lower PLT concentration $(1.99 \mathrm{x})^{11)}$. In practice, there is evidence that positive clinical outcomes in knee OA can be obtained with relatively low PLT concentrations ${ }^{20}$. In the present study, although three times more PLTs were found in the Ycellbio PRP ${ }^{\circledR}$ kit (Group II), similar clinical results were obtained with the Easy PRP ${ }^{\circledR}$ kit (Group I). Consequently, PRP has multifactorial efficacy, including PLT granule secretion and leucocyte (and subtype) concentration.

In a meta-analysis, it was suggested that PRP injections significantly improve functional status in patients with degenerative knee pathology, and the beneficial effect was maintained for one year after treatment. It was added that the effectiveness of PRP was derived from a biological benefit which could not simply be explained by the placebo effect ${ }^{21)}$. Scientific evidence is currently insufficient to suggest optimal PLT concentration for the treatment of knee OA and requires further investigation. Patel et al. compared the effects of one or two injections of PRP with a normal saline injection (as a control) in knee OA. According to their results, a single injection of PRP was shown to be as effective as two injections, and both were more effective than a normal saline injection ${ }^{22}$. Another study, conducted by Raeissadat et al. examined the effects of two injections of leucocyte-rich PRP (LR-PRP) separated by a four-week interval. Results indicated improvement in pain, stiffness, and functional capacity of patients with knee OA after six months. Improvements in quality of life after injections were significant. These changes were more significant in physical domains, including role limitation due to physical health, pain and physical functioning ${ }^{14)}$. To date, there are no clear data about intervals between injections of PRP or frequency of injection. In this study, two injections of two different PRP-kits, with a four-week interval in between, revealed no difference in terms of WOMAC and VAS scores.

The use of local anesthesia for PRP injections is controversial. In vitro, local anesthetics have been shown to decrease the positive effects of $\mathrm{PRP}^{23}$. Furthermore, the chondrotoxicity of local anesthetics has been shown in multiple studies ${ }^{24,25)}$. In order to avoid negative impacts, no local anesthetic was administered intra-articularly; instead, a local anesthetic was applied at the injection site for patient comfort.

We recognize two major limitations of our study. The first major limitation was the retrospective design of our study, which restricted our sample size. The second major limitation was that biochemical changes of each PRP kit could not be evaluated.

As a result, similar clinical outcomes may be obtained with PRP kits containing different numbers of PLTs; we found receiving $1,000,000 \mathrm{PLTs} / \mu 1$ to be sufficient for pain relief and functional recovery in treatment of early stage knee osteoarthritis.

\section{REFERENCES}

1) Lane NE, Brandt K, Hawker G, et al.: OARSI-FDA initiative: defining the disease state of osteoarthritis. Osteoarthritis Cartilage, 2011, 19: 478-482. [Medline] [CrossRef]

2) Carr AJ, Robertsson O, Graves S, et al.: Knee replacement. Lancet, 2012, 379: 1331-1340. [Medline] [CrossRef]

3) Zhang W, Moskowitz RW, Nuki G, et al.: OARSI recommendations for the management of hip and knee osteoarthritis, Part II: OARSI evidence-based, expert consensus guidelines. Osteoarthritis Cartilage, 2008, 16: 137-162. [Medline] [CrossRef]

4) Hepper CT, Halvorson JJ, Duncan ST, et al.: The efficacy and duration of intra-articular corticosteroid injection for knee osteoarthritis: a systematic review of level I studies. J Am Acad Orthop Surg, 2009, 17: 638-646. [Medline] [CrossRef]

5) Mishra A, Harmon K, Woodall J, et al.: Sports medicine applications of platelet rich plasma. Curr Pharm Biotechnol, 2012, 13: 1185-1195. [Medline] [CrossRef]

6) Andia I, Sánchez M, Maffulli N: Joint pathology and platelet-rich plasma therapies. Expert Opin Biol Ther, 2012, 12: 7-22. [Medline] [CrossRef]

7) Woodell-May JE, Pietrzak WS: Platelet-rich plasma in orthopaedics. In: Pietrzak WS (ed.), Orthopedic biology and medicine: muskuloskeletal tissue regeneration. Totawa: Humana Press, 2008, pp 47-568.

8) Foster TE, Puskas BL, Mandelbaum BR, et al.: Platelet-rich plasma: from basic science to clinical applications. Am J Sports Med, 2009, 37: 2259-2272. [Medline] [CrossRef]

9) Boswell SG, Cole BJ, Sundman EA, et al.: Platelet-rich plasma: a milieu of bioactive factors. Arthroscopy, 2012, 28: 429-439. [Medline] [CrossRef]

10) Mishra A, Woodall J Jr, Vieira A: Treatment of tendon and muscle using platelet-rich plasma. Clin Sports Med, 2009, 28: 113-125. [Medline] [CrossRef]

11) Sundman EA, Cole BJ, Fortier LA: Growth factor and catabolic cytokine concentrations are influenced by the cellular composition of platelet-rich plasma. Am J Sports Med, 2011, 39: 2135-2140. [Medline] [CrossRef]

12) McConnell S, Kolopack P, Davis AM: The Western Ontario and McMaster Universities Osteoarthritis Index (WOMAC): a review of its utility and measurement properties. Arthritis Rheum, 2001, 45: 453-461. [Medline] [CrossRef]

13) Pourcho AM, Smith J, Wisniewski SJ, et al.: Intraarticular platelet-rich plasma injection in the treatment of knee osteoarthritis: review and recommendations. Am J Phys Med Rehabil, 2014, 93: S108-S121. [Medline] [CrossRef]

14) Raeissadat SA, Rayegani SM, Babaee M, et al.: The effect of platelet-rich plasma on pain, function, and quality of life of patients with knee osteoarthritis. Pain Res Treat, 2013, 2013: 165967. [Medline] 
15) Crane D, Everts P: Platelet rich plasma (PRP) matrix grafts. Pract Pain Manag, 2009, 8: 12-26.

16) Sampson S, Reed M, Silvers H, et al.: Injection of platelet-rich plasma in patients with primary and secondary knee osteoarthritis: a pilot study. Am J Phys Med Rehabil, 2010, 89: 961-969. [Medline] [CrossRef]

17) Lippi G, Salvagno GL, Montagnana M, et al.: Influence of the needle bore size on platelet count and routine coagulation testing. Blood Coagul Fibrinolysis, 2006, 17: 557-561. [Medline] [CrossRef]

18) Dohan Ehrenfest DM, Rasmusson L, Albrektsson T: Classification of platelet concentrates: from pure platelet-rich plasma (P-PRP) to leucocyte- and plateletrich fibrin (L-PRF). Trends Biotechnol, 2009, 27: 158-167. [Medline] [CrossRef]

19) Sánchez M, Azofra J, Anitua E, et al.: Plasma rich in growth factors to treat an articular cartilage avulsion: a case report. Med Sci Sports Exerc, 2003, 35: 1648-1652. [Medline] [CrossRef]

20) Filardo G, Kon E, Pereira Ruiz MT, et al.: Platelet-rich plasma intra-articular injections for cartilage degeneration and osteoarthritis: single- versus doublespinning approach. Knee Surg Sports Traumatol Arthrosc, 2012, 20: 2082-2091. [Medline] [CrossRef]

21) Chang KV, Hung CY, Aliwarga F, et al.: Comparative effectiveness of platelet-rich plasma injections for treating knee joint cartilage degenerative pathology: a systematic review and meta-analysis. Arch Phys Med Rehabil, 2014, 95: 562-575. [Medline] [CrossRef]

22) Patel S, Dhillon MS, Aggarwal S, et al.: Treatment with platelet-rich plasma is more effective than placebo for knee osteoarthritis: a prospective, double-blind, randomized trial. Am J Sports Med, 2013, 41: 356-364. [Medline] [CrossRef]

23) Carofino B, Chowaniec DM, McCarthy MB, et al.: Corticosteroids and local anesthetics decrease positive effects of platelet-rich plasma: an in vitro study on human tendon cells. Arthroscopy, 2012, 28: 711-719. [Medline] [CrossRef]

24) Dragoo JL, Braun HJ, Kim HJ, et al.: The in vitro chondrotoxicity of single-dose local anesthetics. Am J Sports Med, 2012, 40: 794-799. [Medline] [CrossRef]

25) Piper SL, Kramer JD, Kim HT, et al.: Effects of local anesthetics on articular cartilage. Am J Sports Med, 2011, 39: 2245-2253. [Medline] [CrossRef] 